\title{
La Conquista de Jerusalén en su contexto: sobre el personaje colectivo y una vuelta más a la atribución cervantina
}

\author{
Juan CEREZO SOLER \\ Universidad Autónoma de Madrid \\ juan.cerezosoler@gmail.com
}

\section{RESUMEN}

Desde su descubrimiento, La conquista de Jerusalén ha ido ligada al nombre de Miguel de Cervantes. Numerosos especialistas han dado cuenta de las semejanzas que hay entre esta comedia anónima y las obras de teatro de Cervantes, haciendo extensibles los parecidos a toda la producción cervantina. En el presente estudio propongo un acercamiento a esta relación desde una perspectiva menos objetiva, centrándome en aspectos temáticos y argumentales que tienen en común las obras del primer teatro cervantino con la que se custodia en la Biblioteca de Palacio.

Palabras clave: Jerusalem, Cervantes, teatro, Biblioteca de Palacio

\begin{abstract}
Since its discovery La conquista de Jerusalén has been connected to the name of Miguel de Cervantes. Many specialists have accounted for the similarities between this anonymous comedy and the plays by Cervantes, extending them to the rest of his writing. In the present study I propose an approach to this relationship from a less objective perspective, focusing on theme and plotting aspects which are common to Cervantes' early plays and the piece kept in the Palace Library.
\end{abstract}

Key words: Jerusalem, Cervantes, theatre, Palace Library.

Tanto los estudiosos del teatro anterior a Lope de Vega como los especialistas en la obra de Cervantes tienen en La conquista de Jerusalén por Godofre de Bullón un ejemplar raro y digno de atención. Los primeros porque en ella se plasman todos los rasgos de un teatro en plena época de cambio y que aún está luchando por 
configurarse $^{1}$. Los segundos porque la obra carga desde su descubrimiento ${ }^{2}$ y primera publicación con una hipótesis sobre su posible autoría. Esta hipótesis, sólida desde su lanzamiento, parte de la mención que hace Cervantes de una de sus obras titulada "La Jerusalem" en la adjunta al Viaje del Parnaso ${ }^{3}$. Sobre esto, su descubridor, Stefano Arata, expuso en su momento diversos argumentos a favor de la paternidad cervantina, argumentos que constataron los puntos comunes entre la obra de la Real Biblioteca de Palacio y las que se conservan de esta época de actividad teatral cervantina: en el ámbito formal señala las semejanzas que atañen a la métrica, a la configuración del reparto o al tipo de acotaciones utilizadas; en cuanto al contenido, apunta el comportamiento de las figuras alegórico-morales, que permiten una aproximación al teatro cervantino, y añade una lectura histórica de la obra, no exenta de intencionalidad política por parte del autor ${ }^{4}$.

Durante las décadas posteriores, estos argumentos se han visto ampliados y reforzados por los estudiosos que han sucedido a Arata en el intento de incluir esta comedia en el conjunto de obras de Cervantes. Los trabajos de Héctor Brioso ${ }^{5}$ respaldan de manera convincente la autoría del alcalaíno y llegan a su culmen con una edición crítica de la comedia en $2009^{6}$. En ella no solo se recopilan todas las investigaciones sobre el tema publicadas hasta el momento, sino que se proponen nuevos datos que vinculan el nombre del complutense con la obra custodiada en la Real Biblioteca ${ }^{7}$. Junto a él está el profesor José Montero, que también ha defendido

\footnotetext{
${ }^{1}$ Así lo demuestra, por ejemplo, el hecho de que fuera inicialmente compuesta en cuatro jornadas, aunque nos ha llegado refundida en tres. La tercera y última es considerablemente superior en el número de versos a las dos primeras, lo que permite pensar que el resultado fue fruto de una reelaboración por parte de su autor, vacilante en una época previa a la regla lopesca de las tres jornadas. Cf. S. Arata (1997), p. 56.

2 Pertenece a una colección de obras teatrales y se guarda en la Biblioteca de Palacio. Cf. P. C. Rojo Alique (1996-98), pp. 83-131. Dentro de los tres mil manuscritos que guarda esta biblioteca, para un acercamiento a los que contienen obras de teatro cf. S. Arata (1989); (1991), pp. 3-15; y (1996), pp. 7-24.
}

${ }^{3}$ Viaje del Parnaso, adjunta, edición de las Obras Completas de Cervantes por F. Sevilla y A. Rey Hazas (1995), p. 1350. Todo el teatro cervantino que utilizamos lo tomamos de esta edición. En lo sucesivo señalaremos entre paréntesis, en el cuerpo del texto, las siglas, jornada y los versos que citamos.

${ }^{4}$ Cf. S. Arata (1992), pp. 9-112; y (1997), pp. 53-66.

${ }^{5}$ H. Brioso (2009a) y (2010).

${ }^{6}$ De esta edición de La conquista salen todas las citas en el presente estudio, con subrayado nuestro.

${ }^{7}$ Señala H. Brioso, por ejemplo, que de las primeras obras teatrales de Cervantes, varias son las que representan "ambientes morunos o turquescos, aparece un mundo musulmán en distintos grados de alejamiento o proyección en el tiempo", (2009b) p. 98. A propósito de las conexiones entre La Galatea y La conquista, el estudioso apunta que uno de los tres sonetos que abre la novela es de Gálvez de Montalvo, cortesano, escritor y amigo de 
en varios lugares la hipótesis lanzada por el hispanista italiano y ha reforzado los argumentos existentes incidiendo particularmente en la proximidad de varios versos de la obra anónima con otros de Cervantes ${ }^{8}$. Del mismo modo, Alfredo Rodríguez López-Vázquez ${ }^{9}$ y Alfredo Baras Escolá ${ }^{10}$ han hecho sus propuestas -todas importantes- en este sentido. Se les añade, en los últimos años, la aportación de Aaron M. Kahn, para quien la defensa de la tesis cervantina parte del análisis del carácter ideológico de La conquista de Jerusalén en relación con el enfrentamiento entre la corona española y el islam, y se centra fundamentalmente en las figuras alegóricas que pueblan tanto la obra anónima como las cervantinas ${ }^{11}$. Un importante acierto de este crítico es el de incluir un apartado con otros posibles candidatos, demostrando las afinidades de forma y contenido entre el teatro de Cervantes y $L a$ conquista de Jerusalén ${ }^{12}$. El último de los críticos en seguir el camino abierto por Arata es Moisés R. Castillo, que conecta hábilmente un gran número de "aspectos temáticos, dramáticos, e ideológicos" con "las comedias de cautivos cervantinas $E l$ trato de Argel, La gran sultana y Los baños de Argel", demostrando que "tanto La conquista como las comedias de cautiverio cervantinas recrean situaciones vitales en un marco fronterizo de enfrentamiento bélico, donde las debilidades humanas de cristianos y de musulmanes contrastan con el exagerado fervor religioso del que alardean muchos personajes cristianos" ${ }^{\prime 13}$.

Por oposición, hay algunos estudiosos que todavía muestran cautela a la hora de otorgar a La conquista la condición de cervantina. Jean Canavaggio ${ }^{14}$ es uno de los

Cervantes que a finales de la década de 1580 andaba ocupado en la traducción de la Gerusalemme liberata, poema largo de Tasso en el que se basa la comedia anónima. Los datos vuelven a unir al padre del Quijote con La conquista de Jerusalén. (2009b), pp. 100101 .

${ }^{8}$ J. Montero Reguera, (1994-95), pp. 83-87; (1995-97), pp. 361-366.

${ }^{9}$ Por señalar un pasaje que ilustra a la perfección su propuesta: "En principio la mera comparación estadística debería bastarnos para atribuirle la obra a Cervantes sin mayores dudas, pero un análisis más fino de ese mismo repertorio refuerza de forma drástica esta primera impresión”, A. Rodríguez López-Vázquez (2011).

${ }^{10}$ Este autor no alberga dudas posibles sobre la pertenencia de La conquista al conjunto del teatro de Cervantes. Señala paralelismos cuya "coincidencia es tal que certifica sin más la autoría cervantina”. A. Baras Escolá (2010), p. 80.

${ }_{11}^{11}$ A. M. Kahn (2010), p. 104 y p. 116.

${ }^{12}$ Resultan esclarecedoras las conclusiones en las que se desechan el resto de dramaturgos como candidatos, bien con base en el número de caracteres o de versos, bien en la definición de los personajes alegóricos. A. M. Kahn (2010), p. 121.

${ }^{13}$ M. R. Castillo (2013), p. 128

14 "Tampoco podemos atribuir a Cervantes, al menos con plena seguridad, una comedia recientemente encontrada por el llorado Stefano Arata en los fondos de la Biblioteca de Palacio, La conquista de Jerusalén por Godofre de Bullón, a pesar de tener su título cierto 
más precavidos en este punto, si bien no llega a rechazar completamente la posibilidad de que Cervantes sea su verdadero autor. Rechazo, por otra parte, que sí manifiesta Eisenberg al no ver la concordancia entre la mención de la adjunta al Viaje del Parnaso y el título de la comedia, al tiempo que señala que

La conquista de Jerusalén ensalza a un francés, Godofre de Bullón, y Cervantes jamás elogia a ningún francés. La obra no contiene ni un solo soldado español ni una referencia a España, y ello no es compatible con el patriotismo expresado en La Numancia y en el Trato de Argel, comedias supuestamente contemporáneas a La Jerusalem ${ }^{15}$.

Sin embargo, no es el objeto de las siguientes páginas dibujar con detalle el panorama crítico en el que esta comedia se encuentra ${ }^{16}$. Los objetivos del presente estudio son, en primer lugar, señalar algunas semejanzas más entre La conquista y las obras de Miguel de Cervantes ${ }^{17}$. En segundo lugar, se intentará poner de relieve la existencia de un personaje colectivo, desatendido hasta ahora. La configuración e instrumentalización de este personaje colectivo -realidad teatral vigente de la que Cervantes, sabemos, tomó buena nota- que aparece en La conquista de Jerusalén es fácilmente vinculable con la del primer teatro cervantino, sobre todo, con $L a$ Numancia. Si a esta comparación se le añade el cotejo con otra obra coetánea, también de cariz histórico, como es La destruyción de Constantinopla, de Lobo Lasso de la Vega, podrá verse que La conquista presenta actitudes exclusivamente cervantinas en su composición. En definitiva, se intentará demostrar que las semejanzas entre el teatro de Cervantes y La conquista de Jerusalén trascienden las puras semejanzas formales y representan expresiones comunes, coincidencias que afectan a todo el hecho teatral desde el inicio de su planteamiento.

parentesco con el de La Jerusalén, citada entre las comedias que se mencionan en la Adjunta al Parnaso", J. Canavaggio (2000), pp. 54-55.

${ }^{15}$ D. Eisenberg (2003), p. 15.

${ }^{16}$ Panorama nada numeroso, por otro lado. Se han señalado varias causas posibles de este silencio crítico. Para Brioso Sánchez y Brioso Santos (2007), p. 165-166 está el "poco interés y los muchos prejuicios que suele despertar la producción teatral cervantina". Para A. Kahn (2010), p. 101, es el desconocimiento de la obra el que justifica la escasez de estudios y para M. R. Castillo (2013), p. 123 "la reticencia por parte de los estudiosos podría muy bien deberse al numeroso elenco de atribuciones cervantinas falsas, así como a la dificultad que siempre entraña analizar las comedias de Cervantes".

${ }^{17}$ Se continúa en el presente trabajo con la línea de argumentación presentada en el II Congreso Internacional de Jóvenes Investigadores del Siglo de Oro cuyas actas se encuentran, actualmente, en prensa. J. Cerezo Soler (2013). 
La expresión literaria de la experiencia de cautiverio ${ }^{18}$ está presente en gran parte de los escritos de Cervantes. Por lo tanto, presenciar la falta de libertad en el marco de una guerra con trasfondo religioso, además, en una obra datada en la década de 1580, recién liberado de su prisión en Argel, debe poner al estudioso en guardia ante los posibles visos cervantinos. Dentro del tratamiento que el complutense da al tema del cautiverio, un rasgo importante es que los personajes apresados sufren la falta de libertad en dos niveles: el físico cuando son capturados por el enemigo, y el espiritual cuando son enamorados. Este esquema procede directamente de fuentes literarias griegas y bizantinas, y Cervantes lo explota insistentemente en sus composiciones teatrales, aunque siempre dentro del contexto de tensión bélica contra el musulmán ${ }^{19}$. La construcción del enredo amoroso en ambientes de cautiverio y protagonizado por cautivos es muy similar en las obras de Cervantes y en La conquista de Jerusalén: cautivos que se enamoran de sus captores y viceversa. En la obra anónima de Palacio se presencia la pasión que siente Erminia por Tancredo, general cristiano, que la tuvo prisionera en un tiempo pasado. Tancredo da relación de lo que sucedió:

\author{
Por esto y por pagar[le] un blando y tierno \\ amor que me mostraba, quise darle \\ la dulce libertad sin premio alguno; $[\ldots]$ \\ Y si por dicha esta ciudad se toma \\ -que se hará con el favor del cielo-, \\ y Erminia acaso a mi poder tornase, \\ otra vez y otras ciento gozaría \\ la alegre libertad sin interese ( $C J$, II, 700-703; 706-710).
}

Tancredo, puesto que ha cautivado involuntariamente el espíritu de Erminia, la libera de su prisión física. Esto interesa en la medida en que asistimos, un poco más

\footnotetext{
${ }^{18}$ No en vano "las cuatro comedias que desarrollan el tema del cautiverio constituyen, como es sabido, el grupo temático más definido y amplio del quehacer cervantino [...] y ello es así, probablemente, a causa de la vinculación directa que hay entre dichas obras dramáticas y la experiencia biográfica de Cervantes como cautivo en Argel”. A. Rey (1993), p. 29.

${ }_{19}$ En los años en los que se redacta La conquista están teniendo lugar cambios en el tratamiento del tema del cautiverio. Estos cambios se resumen en una evolución de la visión idealizada hacia una visión realista, en la que se señalan todas las notas trágicas del cautiverio real. Así, en La selva de aventuras, de Jerónimo Contreras, publicada en 1565, se introduce por primera vez un episodio de cautiverio ambientado en Argel, G. Camamis (1977), p. 39. Este autor propone 1580 para "establecer una línea fronteriza entre lo literario y lo histórico", aunque más tarde se ha señalado que esta fecha "no se corresponde con los sucesos bélicos por un lado, ni con las referencias literarias por otro". M. A. Teijeiro Fuentes (1987), p. 12. Sea como sea, es innegable que Cervantes introduce importantes dosis de realismo en sus reelaboraciones ficticias del cautiverio.
} 
adelante, al momento en que se reencuentran: Erminia disfrazada de Clorinda y Tancredo persuadido de que está viendo a aquella de quien realmente está enamorado. Se da entre ellos el siguiente parlamento:

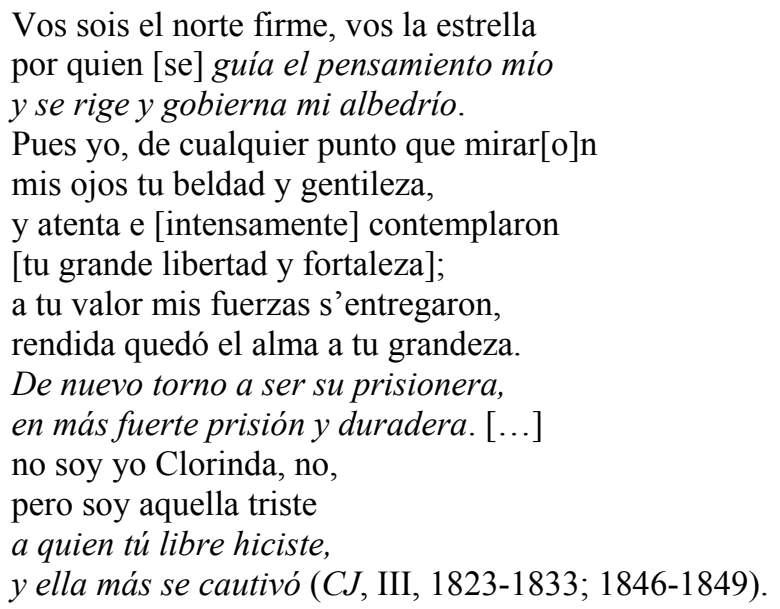

No deja de llamar la atención que Erminia refiera su pasión amorosa como "más fuerte prisión y duradera" que la prisión física, la que solo limita la libertad corporal. Si con esto queda señalada la comparación entre sendos tipos de cautiverio como dos planos en los que se pierde libertad, hay que mencionar que no es el único recurso de entrelazamiento entre amor y cautiverio, ni en la literatura de Cervantes ni en La conquista. Puede verse, por ejemplo, que a través del sentimiento amoroso los personajes experimenten no un cautiverio espiritual, sino una liberación, una ruptura interna de las cadenas que sí se mantienen en el plano físico. Buena muestra de ello es la escena en la que Solinda y Eustaquio, cautivos cristianos, departen sobre su suerte justo en el momento en que son ejecutados

\author{
mas pues quiso mi suerte \\ que fueses de mí seguida \\ con solo el alma en la vida \\ con alma y cuerpo en la muerte, \\ contento y alegre muero, \\ y soy bien afortunado \\ solo por morir al lado \\ de la vida que [más] quiero (CJ, I, 584-592).
}

Siguiendo, el espectador también puede asistir a un cambio de papeles auspiciado bajo los efectos que el amor ocasiona en los personajes. El captor se vuelve, de esta manera, en cautivo de su propia presa. Al final de la segunda jornada, queda Tancredo solo y en su monólogo habla de sus anhelos hacia la persona de Clorinda 
Quizá la cautivaré,

y si esto el cielo me envía,

no usaré la cortesía

que ya con Erminia usé;

y allí rendirá el amor,

con la potencia en que estriba,

el señor a la cautiva,

no la cautiva al señor (CJ, II, 1320-1327).

Por último, el más rico de los pasajes en el tratamiento de esta cautividad amorosa viene con la conversación entre Erminia y Tancredo, en la jornada tercera, citado parcialmente unas líneas más arriba. Erminia reprocha a Tancredo que "Ansí qu'estás obligado | a mirar por tu cautiva $\mid$ y procurarla que viva $\mid$ como señor bien mirado" (CJ, III, 1934-1937), y este, en un alarde de elocuencia, contesta que

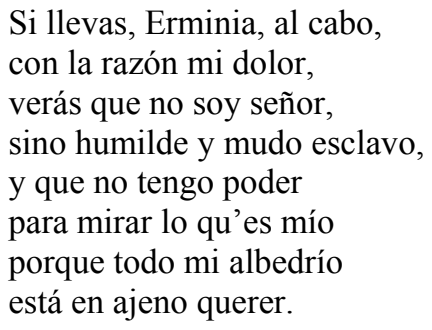

Los ejemplos aquí mostrados tienen importantes ecos en la literatura dramática cervantina, sobre todo en las obras en las que, bien a través de la ambientación o bien a través del tipo de personajes, se incurre en la realidad del cautiverio norteafricano. En Los tratos de Argel, Los baños de Argel, La gran sultana o El gallardo español, en todas ellas se plasman situaciones muy similares a las referenciadas de La conquista de Jerusalén, llegando incluso al pasaje textual casi idéntico ${ }^{20}$.

${ }^{20}$ En las obras de Cervantes abundan los pasajes en los que se entrelaza el amor y el cautiverio, en cualquiera de las expresiones señaladas. Así, para constatar el doble cautiverio, el lector puede ver El gallardo español (GA), vv. 1540-1553; La gran sultana (GS), vv. 490-497; El trato de Argel (TA), vv. 25-36 y 289-292. Para la visión cervantina en la que el amor promueve un sentimiento de libertad espiritual, GA, vv. 1851-1852 y 19982002; Los baños de Argel (BA), vv. 2665-2679 y TA, vv. 309-310. Por último y, quizá, más interesante, es el cambio de roles que a través del amor se da en los personajes. En $B A$, vv. 2939-2943; $G S$, vv. 709-711, 1323-1330, 2425-2430 o $T A$, vv. 1083-1094 y 1107-1118. No recogemos aquí las citas completas por cuestiones de espacio. Para un acercamiento comparativo a este tema con algunos ejemplos cf. J. Cerezo Soler (2013), pp. 79-93. 
Sin salir de este universo literario en el que la libertad juega un papel clave, es tremendamente significativa la forma de tratar en La conquista los vaticinios y las premoniciones, casi siempre fatales para los personajes. La presencia del augurio planea constantemente sobre las cabezas de los protagonistas y ataca frontalmente el celo por su libre individualidad. En La Numancia una predicción poco alentadora $^{21}$ hace perder la compostura de uno de los personajes en escena, y Leoncio opinará al respecto:

\author{
iQue todas son ilusiones, \\ quimeras y fantasias, \\ agüeros y hechicerías, \\ diabólicas invenciones! \\ No muestres que tienes poca \\ ciencia en creer desconciertos; \\ que poco cuidan los muertos \\ de lo que a los vivos toca (CN, II, 1097-1104).
}

Cervantes disfruta rechazando toda superstición, sobre todo si tiene que ver con el futuro inmediato de sus personajes y propone una continua afirmación, en muchos casos vehemente, de su total libertad de acción. El pasaje, además, ilustra a la perfección el tratamiento cervantino del destino, de su relevancia dramática y, sobre todo, del violento debate que plantea a los personajes el tener que tomar decisiones a sabiendas de que su futuro está ya predeterminado ${ }^{22}$. Pues bien, en La conquista se encuentran abundantes intervenciones en las que la misma idea es tratada de forma más que similar. Reunidos, en la segunda jornada, el rey de Jerusalén, su adivino Marsenio, Argante y Clorinda; tiene lugar una interesante discusión en la que Clorinda, tomando la palabra, se dirige a su señor en estos términos:

Digo, señor, que oprobias y que abajas

tu nombre y tu valor con lo que haces

\footnotetext{
${ }^{21}$ Sobre todo el pasaje, en el que el hechicero Marquino hace hablar a un cadáver para escuchar la suerte que correrá el pueblo numantino tras el asedio romano, S. Zimic (1992) escribe que "Cervantes lo utiliza como símbolo gráfico de una débil y última esperanza que revive momentáneamente para apagarse después para siempre”, p. 73. La premonición no solo preocupa a Morandro, sino que desespera también a Marquino, que se arroja a la sepultura suicidándose.

${ }^{22}$ Escribe A. Rey Hazas (1999) que "a pesar de las diferencias temporales y temáticas que parecen distanciar a Los tratos de Argel de La Numancia, ambas piezas primerizas tienen el mismo objeto: analizar la libertad individual y colectiva del hombre cuando está amenazada por las más adversas circunstancias, para defender, en ambos casos, la posibilidad de mantenerla aun en el límite más extremo", p.121.
} 
si a estas burlerías torpes, bajas,

crédito das y así te satisfaces [...].

Toma, señor, la espada, el arnés toma

y deja los hechizos falsos, vanos,

que los que se han de usar en esta parte

son la industria y [el] furor [de] Marte (CJ, II, 746-749; 758-761).

Marsenio, hechicero del rey, le previene, pues sostiene que el hacer caso al consejo de Clorinda y usar de misericordia con los cristianos sin obedecer lo que el augurio ha dicho será un error irreparable, a lo que Clorinda se defiende

Si viene a la verdad tu ciencia justa, dime si tus carateres perfetos te dicen y señalan, por ventura, algún gran bien o presta desventura

Marsenio: Feliz reposo me asegura el cielo, larga, dichosa y descansada vida; de repentina muerte no recelo, de cautiverio o enfermedad mecida.

Clorinda: ¿Si pruebo que mientes? [...]

Llegue a tu corazón la daga mía, que mentirosa hará tu astrología (CJ, II, 774-785).

Así, con violencia, demuestra Clorinda el fallo del vaticinio. Desmiente al hechicero y evidencia la falibilidad de su magia, al tiempo que hace alarde de la más rabiosa y profunda libertad. Libertad que reafirmará en la III y última jornada, durante la conversación entre ella y un eunuco llamado Argente. Clorinda se prepara para un ataque al campamento cristiano cuando Argente le previene de una visión que tuvo hace años en la que la protagonista se convertía al cristianismo y, acto seguido, moría. Por respuesta, el eunuco lo único que recibe es "tanto más esta salida | m'encita y pone cuidado, | que si he querido hasta aquí | por mí sola señalarme" (CJ, III, 2178-2181).

Queda para el final uno de los rasgos más llamativos de La conquista de Jerusalén, rasgo que, además, permite una conexión clara con el quehacer dramático cervantino. Es la presencia de un personaje colectivo y el papel que juega en el desarrollo de la acción. Hay en el teatro de Cervantes una presencia clara y concreta de una identidad colectiva: se trata de La Numancia, primordialmente, y de Los tratos de Argel, en menor medida. En La Numancia, que será la que aquí se utilice como referencia, el personaje colectivo está conscientemente configurado 
desde el mismo inicio de la obra ${ }^{23}$. Con ello, Cervantes persigue que el espectador relacione intuitivamente el comportamiento ejemplar de los numantinos con el que tienen, o deben tener, los españoles del siglo $\mathrm{XVI}^{24}$. En La conquista de Jerusalén no solo puede distinguirse la presencia de una colectividad, sino que puede verse que es una colectividad con aires bastante cervantinos. Ya desde la conversación inicial que mantienen los personajes alegóricos se identifica al bando cristiano como un todo, sin separaciones, y cuyos personajes individuales no logran mermar la sensación de colectividad: "[...] y los que de esta impresa son soldados | les quedará por nombre «los cruzados»" (CJ, I, 135-136). Se hace mención al bando, nombrándose como "los cruzados" antes, incluso, de que se mencione en escena al capitán, a la cabeza individual del bando: "Los cuales, siendo [su] cabeza y guía | Godofre de Bullón, varón prudente" (CJ, I, 137-138).

El momento de verdadera afirmación de este personaje colectivo viene en la III jornada, durante el parlamento entre Godofre de Bullón -representando al bando cristiano-, Clorinda y Argante -al bando moro- y Jaldelio -embajador de Egipto-, parlamento en el que decidirán si van a la guerra entre ellos.
¿Tanto fías, Godofre, en la Fortuna, viendo que yerra aquel que en ella fía?
Pues yo quiero acabar en sola una palabra que declare esta porfía: este doblez desta mi ropa encierra la paz segura y mas segura guerra. [...] Elige la que quieres $(C J$, III, 1578-1584).

Jaldelio propone que sea el general cristiano el que elija el desenlace del parlamento, mostrando un doblez en su vestidura con las dos opciones, "paz" y "guerra". Godofre, dubitativo, comienza su respuesta "Pues yo elijo...". La pregunta se le ha hecho a él, al capitán individual, pero ante un claro titubeo en la respuesta todo su bando toma la palabra, se coloca por encima de él y grita: "¡Guerra, guerra, señor, la guerra elije!" (CJ, III, 1585). Godofre se rinde a la opinión de sus soldados, ya han decidido ellos; él, con toda su individualidad, no puede ahogar la potencia de la colectividad, y concluye el parlamento diciendo: "Elijo pues lo que mi gente dijo" ( $C J$, III, 1586). Poco más adelante, entrando todo

23 "Cervantes concibe desde el primer momento a los habitantes de Numancia como un bloque sin fisuras que se mantiene así, unido, durante todo el discurso de la tragedia hasta su conclusión” A. Rey Hazas (1992), p. 72.

${ }^{24}$ Se trata de una época en que "de algún modo, los dramas vienen a ser la expresión de una autopercepción de la comunidad y de su protagonismo en el devenir de la historia, ya que el pasado se interpreta siempre como una clave para entender el presente o para influir en él" F. J. Burguillo (2013), p. 45. 
el bando cristiano a escena, se les oirá cantar al unísono "Así lo quiere Dios, así lo quiere" ( $C J$, III, acot.), con lo que queda reafirmada, ya sin lugar a dudas, la voz colectiva $^{25}$. El grupo ha tomado partido, la trama se ha desarrollado conforme a lo que ellos, como un bando completo, han opinado; han ejercido su protagonismo y su decisión ha sido primordial para el desenlace de la obra. Concluyendo, este comportamiento colectivo tiene antecedentes claros en las obras de Cervantes ${ }^{26}$, no así en otros dramaturgos de la época, y ponerlas en relación indicia concomitancias que es preciso tener en cuenta, sobre todo cuando, de ser Cervantes el autor, se da en obras de tan cercana cronología ${ }^{27}$.

Finalmente y con el objeto de perfilar un poco más la vinculación cervantina de La conquista de Jerusalén, caben unos apuntes sobre el contexto literario en el que se pergeña esta comedia anónima. Como ya informó Arata, la obra encaja plenamente en la producción del grupo de dramaturgos de 1580, un conjunto que vio "su carrera condicionada por el éxito del joven Lope de Vega, que en pocos años conquistó el favor del público y de los autores de comedias" ${ }^{28}$. De la producción que se conserva de estos años, llama la atención el elevado número de obras que adoptan como asunto un evento histórico pasado, de carácter, por lo general, bélico. Esto responde a una politización del objeto teatral, a una finalidad exclusivamente ideológica. Este teatro experimental estuvo inevitablemente condicionado por las políticas y las tensiones exteriores del imperio:

No es de extrañar, dado el tamaño de sus aspiraciones, que la monarquía recurriese a cuantos medios de difusión, propaganda y legitimación tuviera a su

\footnotetext{
${ }^{25}$ Este es un recurso importante en la plasmación teatral de la colectividad, como apunta $\mathrm{T}$. J. Kirschner (1992), p. 160. "La característica principal que acompaña casi siempre a la masa-actor es la creación del personaje "todos" por medio del cual la masa expresa su común volición hablando en unisón de viva voz. El diálogo de este personaje está marcado por la brevedad de expresión y por la repetición [...] con el estruendo de la voz emitida al mismo tiempo por los miembros componentes de la multitud acumulada en el escenario, el impacto del personaje colectivo es tal que domina por completo la acción. Su volumen y su voz pesan sobre el resto de los personajes, a la vez que afectan al público".

${ }^{26}$ Se ha comparado otras veces la forma cervantina del personaje colectivo con la forma lopesca. En su estudio ya clásico, T. J. Kirschner (1979) escribe que "La trama de Fuenteovejuna consiste en la transformación del pueblo-personaje del conglomerado que forma en las primeras escenas a la masa psicológica del final. [...] El protagonista múltiple pasa de un estado pasivo (en el que cada miembro del personaje colectivo está aún movido por motivos privados) a un estado activo", p. 83. Nada parecido a lo que ya se ha apuntado sobre los personajes colectivos de La Numancia o La conquista de Jerusalén, donde aparecen definidos desde el principio. V. n. 22.

${ }^{27}$ También en La conquista de Jerusalén puede encontrarse lo que el profesor A. Rey Hazas da en llamar "añejo sentido colectivo de las primeras obras cervantinas" (1999), p. 127.

${ }^{28}$ S. Arata (1992), p. 9.
} 
alcance, un proceso que provocó que los fundamentos teóricos, políticos, de la aspiración y del propio reino, se prefundiesen por autores y obras ${ }^{29}$.

Puesto que la monarquía tiene abiertos varios frentes, los aledaños del poder verán en el teatro del siglo un recurso inagotable de arengas y exhortaciones, una importante herramienta propagandística destinada a mantener el esfuerzo bélico en el imaginario colectivo del interior de la península, y, al mismo tiempo, ahogar las voces críticas que puedan surgir. Esto crea una tendencia poética vertebrada en la plasmación de una victoria o de cualquier acontecimiento heroico ${ }^{30}$. Así puede percibirse en La muerte del Rey don Sancho, La libertad de España por Bernardo del Carpio y, sobre todo, en El saco de Roma, todas ellas de Juan de la Cueva; también en La Numancia, de Miguel de Cervantes; en la tragedia de La destruycion de Constantinopla, de Lobo Laso de la Vega; y, por supuesto, en La conquista de Jerusalén. El candente enfrentamiento con el islam permite la comparación entre estas dos últimas obras.

En la obra de Gabriel Lobo Laso de la Vega, el espectador asiste a la caída de Constantinopla tras el asalto de las fuerzas otomanas de Mehmed II, en 1453. La elección de un tema tan alejado cronológicamente del presente en el que se escribe trasciende el carácter recreativo de la obra ${ }^{31}$. Desde esta elección el autor dirige sus esfuerzos a despertar el interés del público en el acontecimiento que se relata. La caída de Constantinopla, conocida de seguro por todos los espectadores, fue la consolidación del imperio otomano como la amenaza que quitaba el sueño de todo habitante español, sobre todo de los residentes en costas mediterráneas. Por ello, Lobo Lasso incidirá particularmente en

el interés que "nosotros" (autor y público -lector, por ahora-) tenemos en lo que se va a representar, puesto que la tragedia, aunque parece lejana en sus implicaciones, ocurre en "nuestro" espacio geográfico, no en un lugar remoto, desconocido y, en consecuencia, carente de consecuencias para "nosotros"32.

\footnotetext{
${ }^{29}$ M. García-Bermejo Giner (2013), p. 85.

${ }^{30}$ La tendencia no solo afecta a la práctica teatral, pues "la cultura de las armas, de los acontecimientos bélicos y de la propia vida de los soldados -que denominamos aquí, en sentido global, cultura de la guerra- fue la materia prima de infinidad de poemas laudatorios, de largas composiciones épicas, de relatos de corte autobiográfico o cronístico". F. J. Burguillo (2013), p. 25.

${ }^{31}$ Como bien escribe A. Hermenegildo (1983), moderno editor de la obra de Lasso, la representación "no parece haber servido unos intereses puramente arqueológicos. Hay, tras la reconstrucción escénica de la catástrofe, unos condicionamientos, ocultos, semiocultos o patentes, que justifican su existencia y llenan el vacío espacio-temporal que va de 1453 a finales del siglo XVI", p. 18-19.

32 A. Hermenegildo (1983), p. 20. Un poco más adelante este editor escribirá que "el contenido profundo del drama es una puesta en guardia del público contra el peligro turco y
} 
El español ha de estar alerta frente a la amenaza musulmana, en este caso, turca; y ha de vigilar su comportamiento, pues de la destrucción de Constantinopla sacada a escena puede extraerse una lección válida para cualquier cristiano súbdito de la corona hispánica:

Esta España tan corrupta -con personas como Janto, las dos rameras y su alcahuete- corre mucho peligro de caer a fuerzas mayores militares como hacía siglo y medio antes Constantinopla había caído a los turcos. Lamenta Lobo que el peligro aún exista. Según Lobo, solamente con reformas universales de la moral España se podrá salvar ${ }^{33}$.

Como se ve, la motivación ideológica de la obra está muy presente desde la elección del motivo literario hasta determinados enunciados, puestos en boca de los personajes. Un caso claro, por mencionar uno, es el sueño en el que a Mahometo (Mehmed II) se le aparecen tres alegorías: Discordia, Ambición y Envidia. Por medio de estas tres, el turco es instado a gobernar no solo Bizancio, sino también "las Españas", y a "ser de todo el orbe obedecido" ( $L a$ destruycion de Constantinopla, v. 294).

En La conquista de Jerusalén también se elige un motivo alejado en el tiempo la conquista de la Ciudad Santa por Godofre de Bullón tuvo lugar en 1099, quinientos años antes de la composición de la obra-. Esta elección se presta cómodamente a la lectura ideológica, como se ha hecho anteriormente ${ }^{34}$. Pero lo que de verdad importa es la correlación que se persigue en la mente del receptor, pues el objeto dramatizado debe ser reconocido por el espectador como un problema actual, y esto se consigue a través de la relación de las dos colectividades: los soldados cristianos que llegan a Jerusalén para liberarla del yugo islámico y los españoles de finales del XVI, que viven activamente un enfrentamiento con una gran potencia musulmana y padecen, en muchos casos, los rigores del conflicto.

sus ramificaciones españolas", p. 21. Demuestra en su estudio que Lasso intenta actualizar el contenido trágico de La destruyción de Constantinopla en aras de implantar en sus espectadores un sentimiento de vigencia, todo en un intento de "«nacionalizar» el problema dramatizado", p. 22.

${ }^{33}$ J. Weiner (2005), p. 71.

${ }^{34}$ Resultan claves las palabras de S. Arata (1992): "En el contexto del traumático abandono de una lucha contra los turcos, la puesta en escena de una obra como La conquista de Jerusalén, que tanto insiste en ofrecer una visión ética y militante de la guerra contra los musulmanes, no parece una mera casualidad. Muy por el contrario, la insistencia en el sufrimiento de los cautivos cristianos, el relieve concedido a personajes como Charles o Enrique, animados por un desinteresado espíritu de cruzada, la exclusión de figuras como Rinaldo y Armida, parecen adquirir un único y claro significado: el de un vehemente alegato en contra del abandono de la lucha contra los turcos”, p. 26. 
Sendos grupos son cristianos en estado de guerra por motivos religiosos. Sin embargo, el recurso utilizado para implantar esta relación en la mente del espectador difiere notablemente en esta comedia de la tragedia de Lobo Laso. En La destruycion de Constantinopla se plasma esta vinculación de una forma explícita, a través de frases y referencias claras que conectan el problema dramatizado con la situación de España; incluso durante la intervención de los personajes alegóricos, estos ejercen una acción directa en el personaje y su mención es manifiesta, como se ha visto unas líneas más arriba. No así en La conquista, que carecerá por completo de alusiones expresas. La fórmula usada aquí es más sutil, menos palmaria, y se limita a la presentación de las virtudes de los soldados cruzados, a su carácter modélico digno de imitación: "Queda Antioquía de temor vacía, | rendida al brío desta ilustre gente: | en fin, a las espaldas no le queda | ciudad contraria que dañarlos pueda" ( $C J$, vv. 141-144); así como la promesa de la libertad de que gozará Jerusalén si estos cristianos tienen parte en su liberación
Este ajuntó cristianos escuadrones, y fue el primero que con santo celo puso en plática y obra esta venida que ha de cobrar tu libertad perdida. Ansí que puedes ya regocijarte, Jerusalén, y hacer júbilo y fiesta y del pesado yugo descargarte que tanto te fatiga y te molesta ( $C J$, vv. 165-172).

Todo se pone en boca de las alegorías, Esperanza y Jerusalén, alegorías que mantienen una conversación aislada y que nunca llegan a tener acción directa sobre el devenir de los personajes ${ }^{35}$. Esto sería argumentación ociosa si la misma relación entre fábula pasada y realidad presente no se diese en La Numancia mediante un proceso idéntico: presentado el asunto, dos personajes alegóricos -España y Dueroestablecerán la correlación, pero lo harán hablando entre ellos, de forma aislada y sin influir en el comportamiento de los protagonistas.

¿Qué envidia y qué temor, España amada,
te tendrán las naciones extranjeras,
en quien tú teñirás tu aguda espada
y tenderás, triunfando, tus banderas! (CN, I, vv.521-524).

Esto, en tanto se dice para el consuelo de la figura alegórica de España, funciona perfectamente como imagen de la relación entre el pasado trágico y el presente

\footnotetext{
${ }^{35}$ H. Brioso (2009b): "Las imaginaciones cervantinas se parecen a las de nuestro anónimo en todo, pero particularmente en que también se mantienen al margen de la acción propiamente humana", p. 88.
} 
glorioso, así como agasajo del público asistente, todos españoles. Los espectadores contemplan el comportamiento heroico de los numantinos y lo reciben como un ejemplo de sacrificio nacional. El caso es más que similar en las dos obras; $L a$ Numancia muestra la ejemplaridad del colectivo que se inmola en una lección destinada a despertar el orgullo nacionalista ${ }^{36}$; La conquista hace exactamente lo mismo sustituyendo esa lección nacionalista por la lección religiosa y el colectivo político-nacional por el colectivo religioso; y, desde luego, el hecho de que sea el recurso alegórico el que sirva para la actualización del motivo histórico vincula una vez más el nombre de Cervantes con esta obra anónima.

Como punto final, baste una mención al carácter provisional de estas páginas. Todo lo que en estudios de este tipo pueda argumentarse está inevitablemente sujeto al hallazgo de pruebas documentales que certifiquen o que desmientan por completo la autoría de La conquista de Jerusalén. Hasta que llegue ese testimonio definitivo, es aconsejable mantener prudencia en la atribución y evitar la afirmación categórica, lo que no impide, eso sí, que se siga estudiando esta obra como una muestra extraña y preciosa del período anterior a Lope de Vega. Un período en el que Miguel de Cervantes, entre tantos otros, disfrutó del éxito y del aplauso del público español, y así lo afirmará, nostálgico, mucho años después.

\section{Obras citadas}

ARATA, Stefano: Los manuscritos teatrales (siglos XVI y XVII) de la Biblioteca de Palacio, Pisa, Giardino, 1989.

-----: «Loyola y Cepeda: Dos dramaturgos del Siglo de Oro en la Biblioteca de Palacio» en Manuscrt.Cao, IV (1991), pp. 3-15.

-----: «La conquista de Jerusalén, Cervantes y la generación teatral de 1580» en Criticón, 54 (1992), pp. 9-112.

-----: «Teatro y coleccionismo teatral a finales del siglo XVI (el conde de Gondomar y Lope de Vega» en Anuario Lope de Vega, 2 (1996), pp. 7-24.

-----: «Notas sobre La conquista de Jerusalén y la transmisión manuscrita del primer teatro cervantino» en Edad de Oro, 16 (1997), pp. 53-66.

BARAS EsCOLÁ, Alfredo: «Los textos de Cervantes. Teatro» en Anales Cervantinos, 42 (2010), pp. 73-88.

\footnotetext{
${ }^{36}$ Al fin y al cabo, Cervantes utiliza el motivo del cerco de Numancia para plasmar que "los míticos numantinos habían consumado de manera rotunda una paradoja histórica con la que el héroe de Lepanto y del cautiverio se sentía particularmente identificado, por razones biográficas obvias, que era la de conseguir la victoria en la derrota, la de vencer a sus vencedores". A. Rey (1999), p. 121.
} 
BRIOSO SÁncheZ, Máximo y BRIOSO SANTOS, Héctor: «De Heliodoro a Tasso y a ¿Cervantes?» en Philología Hispalensis, 21 (2007), pp. 155-172.

BRIOSO SANTOS, Héctor: "A propósito de la historicidad de La conquista de Jerusalén: los cuatro milagros de la primera cruzada» en Anuario de Estudios Cervantinos, 5 (2009), pp. 101-124.

-----: «Análisis métrico de La conquista de Jerusalén por Godofre de Bullón de... ¿Miguel de Cervantes?» en Cuatrocientos años del Arte Nuevo de Hacer Comedias de Lope de Vega [Actas], Vol. 2 (2010), pp. 287-294.

Burguillo, Francisco Javier, "Guerra y milicia en los albores del "Arte nuevo": la "Comedia del saco de Roma" (1579) de Juan de la Cueva» en Del pensamiento al texto. Textualización del saber en el Renacimiento español, Madrid, Academia del Hispanismo, (2013), pp. 23-60.

CAMAMIS, George, Estudios sobre el cautiverio en el Siglo de Oro, Madrid, Editorial Gredos, (1977).

CAnavaggio, Jean: «De un Lope a otro Lope: Cervantes ante el teatro de su tiempo» en Anuario de Lope de Vega, 6 (2000), pp. 51-60

-----: Cervantes, Madrid, Espasa, (2005).

CASTILlO, Moisés R.: «Espacios de ambigüedad en el teatro cervantino: $L a$ conquista de Jerusalén y los dramas de cautiverio» en Cervantes: Bulletin of Cervantes Society of America, 32-2 (2012), pp. 123-142.

CEREzo Soler, Juan: «La conquista de Jerusalén y la literatura de Cervantes. Nuevas semejanzas que respaldan su autoría» en Festina Lente, Actas del II congreso de JISO, Pamplona, Servicio de Publicaciones de la Universidad de Navarra, (2013), pp. 79-93.

Cervantes, Miguel de: Obras Completas, 3 Tomos, Florencio Sevilla y Antonio Rey (eds.), Alcalá de Henares, Centro de Estudios Cervantinos, 1995.

-----[Atribuida]: La conquista de Jerusalén por Godofre de Bullón, Héctor Brioso Santos (ed.), Madrid, Cátedra, 2009.

EISENBERG, Daniel: «¿Qué escribió Cervantes?» en Sobre Cervantes, Diego Martínez Torrón (ed.), Alcalá de Henares, Centro de Estudios Cervantinos, (2003), pp. 9-26.

GARCÍA-BERMEJO GINER, Miguel, «Estando letras y armas en su punto: el teatro y los aledaños del poder en España a fines del siglo XVI» en Del pensamiento al texto. Textualización del saber en el Renacimiento español, Madrid, Academia del Hispanismo, (2013), pp. 85-122.

KAHN, Aaron M.: «Towards a theory of attribution: Is La conquista de Jerusalén by Miguel de Cervantes?», en Journal of European Studies, 40.2 (2010), pp. 99-128.

KIRSCHNER, Teresa J., El protagonista colectivo en Fuenteovejuna, Universidad de Salamanca, (1979). 
-----: «Técnicas de representación de la multitud en el teatro de Lope de Vega» en Encuentros y desencuentros de culturas: desde la Edad Media al siglo XVIII, Actas del XI congreso de la AIH, (1992), pp. 151-161.

LASSO DE LA VEGA, Gabriel, La destruycion de Constantinopla, Alfredo Hermenegildo (ed.), Reichenberg, (1983).

Montero ReguerA, José: reseña a Stefano Arata, «La conquista de Jerusalén [...]» en Manuscrt.Cao, VI (1994-95), pp. 83-87.

-----: «¿Una nueva obra teatral cervantina? Notas en torno a una reciente atribución» en Anales Cervantinos, 33 (1995-1997), pp. 355-366.

REY HAZAS, Antonio: «Cervantes y Lope ante el personaje colectivo: La Numancia frente a Fuenteovejuna» en Cervantes y el teatro. Cuadernos de Teatro Clásico, 7, Madrid (1992), pp. 69-91.

-----: «Las comedias de cautivos de Cervantes», en Los imperios orientales en el teatro del Siglo de Oro. Actas de las XVI Jornadas de Teatro Clásico, Ciudad Real, Univ. de Castilla-La Mancha (1994), pp. 29-56.

-----: «Cervantes se reescribe: Teatro y Novelas Ejemplares» en Criticón, 76 (1999), pp. 119-164.

-----: Poética de la libertad y otras claves cervantinas, Madrid, Eneida, 2005.

RODRÍGUEZ LÓPEZ-VÁZQUEZ, Alfredo: «La Jerusalén de Cervantes: Nuevas pruebas de su autoría» en Artifara: Revista de Lenguas y Literaturas ibéricas y latinoamericanas, 11 (2011).

Rojo Alique, Pedro C.: «Notas acerca del Catálogo de manuscritos de la Biblioteca del Palacio Real de Madrid» en Manuscrt.Cao, VII (1996-1998), pp. 83-131.

TEIJEIRO FueNTES, Miguel Ángel, Moros y turcos en la narrativa áurea. (El tema del cautiverio), Cáceres, Universidad de Extremadura, (1987).

VACCARI, Débora: «Aproximación al contenido de una carpeta inédita de la Biblioteca Nacional de Madrid (Ms/14612/9)» en Campus stellae: haciendo camino en la investigación literaria, Dolores Fernández López, Mónica Domínguez Pérez y Fernando Rodríguez-Gallego, Santiago de Compostela, Vol. 1 (2006), pp. 466-474.

WeIner, Jack, Cuatro Ensayos Sobre Gabriel Lobo Laso De La Vega (1555-1615), Publicaciones de la Universitat de Valencia, (2005).

ZIMIC, Stanislav: El teatro de Cervantes, Madrid, Castalia, 1992. 